$\begin{array}{ll}\text { Abstracta Iranica } & \begin{array}{l}\text { Abstracta Iranica } \\ \text { Revue bibliographique pour le domaine irano-aryen }\end{array} \\ & \text { Volume } \mathbf{3 0} \mid \mathbf{2 0 1 0} \\ & \text { Comptes rendus des publications de } \mathbf{2 0 0 7}\end{array}$

\title{
Passeport à l'iranienne. Paris, Jean-Claude Lattès, 2007, 304 p.
}

Jean-Pierre Digard

\section{(2) OpenEdition}

Journals

Édition électronique

URL : http://journals.openedition.org/abstractairanica/38207

DOI : 10.4000/abstractairanica.38207

ISSN : 1961-960X

Éditeur :

CNRS (UMR 7528 Mondes iraniens et indiens), Éditions de l'IFRI

\section{Édition imprimée}

Date de publication : 8 avril 2010

ISSN : 0240-8910

Référence électronique

Jean-Pierre Digard, «Passeport à l'iranienne. Paris, Jean-Claude Lattès, 2007, 304 p. », Abstracta Iranica [En ligne], Volume 30 | 2010, document 355, mis en ligne le 08 avril 2010, consulté le 26 septembre 2020. URL : http://journals.openedition.org/abstractairanica/38207 ; DOI : https://doi.org/10.4000/ abstractairanica.38207

Ce document a été généré automatiquement le 26 septembre 2020.

Tous droits réservés 


\title{
Passeport à l'iranienne. Paris, Jean- Claude Lattès, 2007, 304 p.
}

\author{
Jean-Pierre Digard
}

En dépit de la mention « roman » portée sur la page de garde, il s'agit d'un témoignage plus ou moins autobiographique, dû à une Iranienne bien connue comme historienne des religions, qui montre avec humour, à travers le récit de dix jours d'une hasardeuse et chaotique course au passeport pour l'étranger, toutes les complications et les subtilités de la vie quotidienne à Téhéran (surtout, à vrai dire, du Téhéran šǐk) sous la République islamique. Rien de très nouveau, donc, dans ce soi-disant «roman ", si ce n'est qu'il se distingue des autres témoignages récents sur l'Iran par des qualités finesse de l'observation, justesse du ton, culture générale, écriture nerveuse et fluide que bien des descriptions ethnographiques pourraient lui envier.

INDEX

Thèmes : 16.1. Iran

\section{AUTEURS}

JEAN-PIERRE DIGARD

CNRS/Mondes iranien et indien - Paris 